\title{
Evaluation potential of PGPR to protect tomato against Fusarium wilt and promote plant growth
}

\author{
Rizwana Begum Syed Nabi ${ }^{1,2 \#, ~ R a h e e m ~ S h a h z a d ~}{ }^{3}$, Rupesh Tayade ${ }^{4}$, Muhammad Shahid ${ }^{1}$, Adil
}

Hussain ${ }^{5}$, Muhammad Waqas Ali ${ }^{6}$, Byung-Wook Yun *1

1 Laboratory of Plant Functional Genomics, School of Applied Biosciences, Kyungpook National University, Daegu 41566, Republic of Korea; ruhii.syed@gmail.com (R.B.S.N); shahidariswat@gmail.com (M.S); bwyun@knu.ac.kr (B.W)

2 Department of Southern Area Crop Science, National Institute of Crop Science, Rural; Development Administration, Miryang 50424, Republic of Korea; rizwananabi@korea.kr (R.B.S.N)

3 Department of Horticulture, The University of Haripur, Haripur, Pakistan raheemshehzad@ymail.com (R.S);

4 Laboratory of Plant Breeding, School of Applied Biosciences, Kyungpook National University, Daegu 41566, Republic of Korea; rupesh.tayade@knu.ac.kr (R.T)

5 Department of Agriculture, Abdul Wali Khan University, Mardan Pakistan, adilhussain@awkum.edu.pk (A.H);

6 School of Biosciences, University of Birmingham, Edgbaston, Birmingham, B15 2TT, UK; waqasali3515@yahoo.com (W.A)

* Correspondence: bwyun@knu.ac.kr; (B.W)

Abstract: Soilborne fungal diseases are most common among vegetable crops and have major implications for crop yield and productivity. Eco-friendly sustainable agriculture practices that can overcome biotic and abiotic stresses are of prime importance. In this study, we evaluated the ability of plant growth-promoting rhizobacterium (PGPR) Bacillus aryabhattai strain SRB02 to control the effects of tomato wilt disease caused by Fusarium oxysporum f. sp. lycopersici (strain KACC40032) and promote plant growth. In vitro bioassays showed significant inhibition of fungal growth by SRB02. Inoculation of susceptible and tolerant tomato cultivars in the presence of SRB02 showed significant protection of the cultivar that was susceptible to infection and promotion of plant growth and biomass production in both of the cultivars. Further analysis of SRB02-treated plants revealed a significantly higher production of amino acids following infection by $F$. oxysporum. Analysis of plant defense hormones after inoculation by the pathogen revealed a significantly higher accumulation of salicylic acid (SA), with a concomitant reduction in jasmonic acid (JA). These results indicate that B. aryabhattai strain SRB02 reduces the effects of Fusarium wilt disease in tomato by modulating endogenous phytohormones and amino acid levels.

Keywords: PGPR; Bacillus aryabhattai; SRB02; Fusarium oxysporum; Tomato wilt; Tomato; Plant growth 


\section{Introduction}

Tomato (Solanum lycopersicum L.) is the second most economically important edible vegetable after potato from the Solanaceae family and is widely cultivated and consumed around the world (Hanson \& Yang, 2016). Tomato is used as a model plant for investigating the genetics and molecular aspects of disease resistance mechanisms. The tomato crop is under threat worldwide owing to biotic and abiotic stresses that have caused significant reductions in yield and productivity. One reason is that tomato is a host for nearly 200 species of plant pathogens, including fungi, bacteria, nematodes, viruses, and others that infect plants at all developmental stages (Stout, Kurabchew \& Leite, 2017), reducing both yield and quality.

Vascular wilt is one of the most important fungal diseases of tomato and occurs wherever these crops are grown. This disease is caused by the soilborne fungus Fusarium oxysporum f. sp. lycopersici (FOL). Three different pathotypes have been identified so far, which can be further classified into three races, 1, 2, and 3, based on various pathogenicity features during infection in tomato. Being soilborne, it is omnipresent and is very hard to get rid of once introduced into the cropping system. If infection occurs at the nursery or seedling stage, plants simply die back, whereas severe losses can occur if the disease appears in the field after transplantation. The fungus can spread in different ways, such as through the transport of infested soil, irrigation water, infected plants and transplants, and seeds (Jones et al., 2014). Infection occurs via the roots, causing serious vascular damage and wilting of the plant that subsequently leads to cell death. In severe infections, more than $80 \%$ of crop loss has been reported (Worku \& Sahe, 2018). Some studies have reported the applicability of protective fungicides as a possible remedy against the different strains of the pathogen. However, the use of chemicals in agriculture has not only raised serious concerns regarding human health and environmental hazards but is also considered responsible for the development of strains that are resistant to these widely used agrochemicals (Zouari et al., 2016). Hence, eco-friendly alternates to chemical measures are needed.

Biological control of plant pathogens has been of great interest to researchers. Apart from pathogenic microbes, plants also have symbiotic or mutualistic interactions with a wide range of soilborne microbes, which protect plants from pathogens either directly or by inducing resistant mechanisms (Pieterse et al., 2014). These microbes associate with the plant roots and help enhance growth-related attributes by improving the uptake of essential ions and minerals, atmospheric nitrogen fixation, and protection from pathogens (Lugtenberg \& Kamilova, 2009). These growth-promoting bacteria are mainly isolated from the rhizosphere of the plants. These microbes are commonly known as plant growth-promoting rhizobacteria (PGPR) (Kloepper, Lifshitz \& Zablotovicz, 1989; Backer et al., 2018) and include organisms such as Pseudomonas spp. Other microbes are known as plant growth-promoting endophytic bacteria, plant growth-promoting fungi, or biocontrol fungi (BCF), including Trichoderma spp. and Sebacinales spp. These can play a role in plant growth and can stimulate plant immune systems (Shoresh, Harman \& Mastouri, 2010; Singh et al., 2019). Endophytes are widely dispersed and can be found in diverse environments including the tropics, temperate zone, aquatics, xerophytics and deserts, tundra, geothermal soils, rainforests, mangroves, and coastal forests. They inhabit plant tissues such as endosperms, roots, leaves, stems, flowers, and fruits (Singh et al., 2017). Generally, plant growth promotion may occur owing to the regulation of the plant hormonal system, modifications in root architecture, production of siderophores, solubilization of soil minerals, activation of secondary mechanisms of plant defense, and production of biochemicals (Pupin \& Nahas, 2014; Backer et al., 2018).

PGPRs and endophytes have a non-pathogenic symbiotic life cycle associated with their host plant tissues; these endophytes can be easily isolated from plant tissues (Arnold \& \& Lutzoni, 2007; Costa et al., 2012). Seeds 
are the source of vertical dispersal of numerous seed-borne endophytes, or PGPRs (Ernst et al., 2003). Along with the alleviation of biotic stress in plants, these PGPRs have been reported to help mitigate a wide range of abiotic stresses as well (Shahzad et al., 2017a). Independent studies have reported the ameliorating effects of PGPRs on plant growth and fungal diseases in tomato and sunflower (Shittu et al., 2009; Waqas et al., 2015). In addition, studies have revealed the remediation abilities of PGPRs in soil contaminated with heavy metals (Jing, He \& Yang, 2007; Bilal et al., 2018). All of these impacts of PGPRs make them widely attractive as biofertilizers and soil microbe mediators (Backer et al., 2018; Rosier, Medeiros \& Bais, 2018). The positive effects of PGPRs on plant growth attributes are well known, but the exact molecular mechanism(s) behind them have not yet been elearly-demonstrated.

PGPRs affect plant growth by either direct or indirect means. The direct promotion of plant growth occurs by a synthesis of complex compounds by the microbes - for instance, phytohormones such as indole-3-acidic acid (IAA), gibberellic acid (GA3), zeatin, and abscisic corrosive (ABA) — or by incremental nutrient accessibility by nitrogen fixation from the surrounding climate, thereby providing supplements for mineral solubilization (Glick, 1995; Bhardwaj et al., 2014). The indirect method of plant growth promotion takes place when PGPRs get involved in reducing the negative effects of one or more phytopathogenic microbes or fungi. This occurs by the production of substantial antagonistic substances or by inducing resistance in plants against the pathogens; for instance, the production of siderophores, hydrogen cyanide (HCN), hydrolytic proteins, etc. (Glick, 1995; Mahmood, Gupta \& Kaiser, 2009).

The role of antifungal PGPRs as biological control agents to control plant diseases has been widely examined. PGPRs are considered either extracellular, including the genera Agrobacterium, Arthrobacter, Azotobacter, Azospirillum, Bacillus, Burkholderia, Chromobacterium, Erwinia, Flavobacterium, Micrococcous, Pseudomonas, and Serratia, or intracellular, including the genera Allorhizobium, Bradyrhizobium, Mesorhizobium, and Rhizobium (Martínez-Viveros et al., 2010; Gouda et al., 2018). The fact that rhizospheric bacteria Bacillus aryabhattai strain B8W22 was previously identified and isolated from cryotubes used for collecting air samples from the earth stratosphere (Shivaji et al., 2009) indicates that these bacteria have cosmic ancestry. Moreover, different strains of the bacterium were isolated from the rhizosphere in South Korea, India, and Tibet (Pailan et al., 2015; Lee et al., 2015; Yun et al., 2016). The plant growthpromoting ability of $B$. aryabhattai was initially reported by (Lee et al., 2012), who demonstrated growth promotion in Xanthium italicum plants. Similarly, Ramesh et al. (2014) (Ramesh et al., 2014) reported on $B$. aryabhattai contributions to plant growth by enhancing the mobilization and bio-fortification of zinc in soybean and wheat. More recently, B. aryabhattai strain SRB02 has been found to play a role in oxidative and nitrosative stress tolerance and promotion of growth in soybean plants by modulating the production of phytohormones (Park et al., 2017a). In addition, B. aryabhattai strains also show the ability for the biosynthesis of thermostable alkaline phosphatase, anti-leukemic tumor-inhibiting L-asparaginase enzyme (Gill et al., 2013; Singh et al., 2014), and degradation of pesticides (Pailan et al., 2015).

In additions, various species of Bacillus have been identified as plant growth--promoting bacteria as well as biocontrol agents against various pathogenic fungi (Compant et al., 2005; Shahzad et al., 2017a). Plant growth--promoting rhizosphere bacteria employ a variety of strategies to facilitate plant growth and survival under pathogenic attack by both direct and indirect mechanisms. The most common direct mechanisms are phytohormone production, the acquisition of nutrients, and the control of pathogens through various means, for example, through the synthesis of hydrolytic enzymes, antifungal compounds, lipopeptides, or antibiotics. The 
indirect mechanisms include protection by triggering of specific defense-related pathways, particularly the induction of systemic resistance (ISR) against pathogens and pests (Khan et al., 2012; Martínez-Hidalgo et al., 2015) and the release of bacterial volatile compounds (Bernier et al., 2011). However, many environmental factors influence the biological control potential of PGPR by either predisposing pathogens to microbial antagonism, regulating the growth or production of metabolites by specific antagonists, or modulating disease development and consequently the level of disease suppression achieved.

From our literature survey, it is evident that except for some reports in crops (Xanthium italicum, soybean, rice, tomato, and wheat) there is a lack of information about the growth-promoting activity of B. aryabhattai and its role in tolerance to biotic and abiotic stress in other plant species (Viljoen et al., 2019; Yoo et al., 2019). In this study, we evaluated the plant growth-promoting abilities of B. aryabhattai SRB02 in tomato cultivars inoculated with phytopathogenic fungus $F O L$.

\section{Materials and Methods}

\subsection{Growth of PGPR and FOL}

B. aryabhattai SRB02 was isolated previously from the rhizosphere of a soybean field in the Chungcheong buk-do region of South Korea (Park et al., 2017b). Bacteria were cultured on LB agar or in broth (AppliChem, Darmstadt, Germany) media at $28^{\circ} \mathrm{C}$ for 24 h. F. oxysporum f. sp. lycopersici strain KACC 40032 was obtained from the Korean Agricultural Culture Collection (KACC, http://genebank.rda.go.kr) and grown on potato dextrose agar plates at $28^{\circ} \mathrm{C}$ for $7 \mathrm{~d}$. The antifungal activity of B. aryabhattai SRB02 against $F O L$ was evaluated following the protocol of (Shahzad et al., 2017a).

Briefly, a $0.5 \mathrm{~cm}^{2}$ disc of active fungal mycelia of $F O L$ was placed at the center of a $90 \mathrm{~mm}$ disposable plastic Petri dish (SPL, Korea) containing LB agar (Becton, Dickinson and Company, France). The overnight bacterial culture of B. aryabhatttai SRB02 was aseptically streaked around the fungal disc at equal distances in a square pattern. For the untreated control, a fungal disc was placed on LB agar, as mentioned earlier, but instead of $B$. aryabhatttai SRB02, only sterile water was streaked. For comparison, the effects of fungal growth inhibition of organic acids against the pathogen were also evaluated. All of the plates were incubated at $28{ }^{\circ} \mathrm{C}$ for $7 \mathrm{~d}$. After the incubation period, the inhibition zone was measured and the percent inhibition was calculated according to the following formula.

Inhibition $\%=\underline{\text { (diameter of fungus on control plate }- \text { diameter of fungus on SRB02 co-cultured plate })} \times 100$ diameter of fungus on control plate

\subsection{Screening of tomato varieties for resistance to $\mathrm{FOL}$}

In the current study, tomato seeds of four Korean cultivars (IT 252842-13 (Cultivar-1), IT 252869-14 (Cultivar-2), IT 260627-16 (Cultivar-3), IT 259462-15 (Cultivar-4)) were selected for their response to the pathogen. Seeds were sterilized with $2.5 \%$ sodium hypochlorite for $10 \mathrm{~min}$ and kept on wet paper towels inside Petri plates in an incubator at $25^{\circ} \mathrm{C}$ for $5 \mathrm{~d}$. Horticultural soil, distilled water, and pots were autoclaved at 121 ${ }^{\circ} \mathrm{C}$ for $20 \mathrm{~min}$. Uniformly germinated seeds were transferred to separate trays filled with sterilized horticultural soil (Soil and Fertilizer Technology, Korea). After one week, uniformly grown seedlings were transplanted to big pots with the dimensions ( $\mathrm{LxWxH})-3.5 \times 3 \times 3$ inches and volume 85-90gm. Plants were allowed to acclimatize for a few days, and the experimental treatments were set up in triplicates, with each replicate 
161 containing at least six plants. The fungal spore suspension of FOL strain KACC 40032 was prepared according

162 to the protocol described by (Lichtenzveig et al., 2006). Control plants were treated with distilled water, and

163 plants were allowed to grow for $5 \mathrm{~d}$. Plants to be treated with the pathogen were inoculated by applying a spore

164 suspension $\left(10^{6}\right.$ conidia $\left./ \mathrm{mL}\right)$ to the exposed roots of tomato plants. The roots were then covered with soil. Plants

165 were allowed to grow at relatively high humidity of $80 \pm 2 \%$. After $14 \mathrm{~d}$ of growth under the conditions

166 mentioned above, the inoculated plants were assessed on the basis of based on symptomatology (severity of

167 plant wilting) and growth.

168

169

170

171

172

173

174

175

176

177

178

\subsection{In planta biocontrol assessment}

After the screening test, two cultivars (resistant and susceptible, one each) were selected based on disease symptoms and growth under biotic stress. Seeds of the selected cultivars were surface-sterilized, germinated, and grown before being transplanted to pots as mentioned previously. The plants were allowed to acclimatize for a few days, and the experimental treatments were set up in triplicate, with each replicate containing at least six plants. SRB02 was applied to plants by soil drenching with $10 \mathrm{~mL}$ SRB02 broth culture $\left(4 \times 10^{8} \mathrm{cfu} / \mathrm{mL}\right)$ in the root zone. The fungal spore suspension FOL strain KACC 40032 was prepared as mentioned previously. Control plants were treated with distilled water, and plants were allowed to grow for $5 \mathrm{~d}$. Plants to be treated with the pathogen were inoculated by applying spore suspension $\left(10^{6}\right.$ conidia $\left./ \mathrm{mL}\right)$ to the exposed roots of tomato plants. The roots were then covered with soil. The plants were allowed to grow at relatively high humidity of $80 \pm 2 \%$ because to further exploit the pathogenic impact of fungus. Data were recorded on growth parameters such as plant height (PH), root length (RL), fresh weight (FW), dry weight (DW), and chlorophyll content (Chl. Cont.) to determine the response of plants to infection in the presence or absence of SRB02. For fresh plant biomasses, the plants were uprooted, carefully washed, and frozen in liquid nitrogen, and then transferred to storage at $-80{ }^{\circ} \mathrm{C}$ until further analysis.

\subsection{Extraction and quantification of amino acid content}

The plant amino acids were extracted according to the protocol described by Khan et al. (2017)(Khan et al., 2017), with some modifications. Briefly, the freeze-dried whole plant samples were ground to homogenate, and $100 \mathrm{mg}$ powdered samples were hydrolyzed under a vacuum in $6 \mathrm{~N} \mathrm{HCl}$ at $110{ }^{\circ} \mathrm{C}$ followed by $80{ }^{\circ} \mathrm{C}$ for $24 \mathrm{~h}$. The dried residue was suspended in $0.02 \mathrm{~N} \mathrm{HCl}$ and filtered through a $0.45 \mu \mathrm{m}$ filter. The amino acids were then quantified using an automatic amino acid analyzer (Hitachi, Japan; L-8900). The experiments were conducted in triplicate, and each replicate was comprised of six plants. The amino acid concentration was determined using relevant standards. Theseis standard known as amino acid standard mixture solution (type $\mathrm{H}$ ) used for the automatic amino acid investigation was procured through Wako Pure Chemical Industries Ltd (Japan), and used for endogenous amino acids assessment.

\subsection{Jasmonic acid quantification}

For the quantification of endogenous jasmonic acid (JA) content, the optimized protocol described by McCloud and Baldwin (1997) was used. Briefly, homogenized powder (0.3 g) from the immediately freezedried whole plant samples was suspended in extraction buffer (70:30 v/v acetone and $50 \mathrm{~mm}$ citric acid), and $25 \mathrm{ng}$ JA internal standard ([9, 10-2 $\left.\mathrm{H}^{2}\right]-9,10$-dihydro-JA) was also added to the suspension. The extract suspension was kept overnight at room temperature for evaporation of highly volatile organic solvents and to 
retain the less-volatile fatty acids. The subsequent aqueous phase was filtered and then extracted with $30 \mathrm{~mL}$ diethyl ether three times. The collective extracts were subsequently loaded onto a solid-phase extraction cartridge (500 mg of sorbent, aminopropyl). In addition, $7.0 \mathrm{~mL}$ of trichloromethane and 2-propanol (2:1 v/v) were used to wash the loaded cartridges. Then, the exogenous JA and relevant standard were eluted with $1 \mathrm{~mL}$ of diethyl ether and acetic acid (98:2 v/v). Following evaporation, the samples were esterified and analyzed by GCMS (6890N network GC system) and a 5973 network mass selective detector (Agilent Technologies, Palo Alto, CA, USA) in the relevant ion mode. The relevant ion mode was selected for JA determination. The ion fragment was examined at $m / z=83$ AMU, corresponding to the base peaks of JA and $\left[9,10-2 \mathrm{H}^{2}\right]-9,10$-dihydroJA. The endogenous JA values were determined from the peak areas with respect tofor relevant standards.

\subsection{Salicylic acid (SA) quantification}

The SA of SRB02-treated tomato plants was extracted and quantified according to the protocol described by (Enyedi et al., 1992; Seskar, Shulaev \& Raskin, 1998). Immediately freeze-dried whole plant tissues were homogenized, and $0.2 \mathrm{~g}$ of homogenate powder was used for the extraction using $90 \%$ and $100 \%$ methanol. The pellets were dried and re-suspended in $2.5 \mathrm{~mL} \mathrm{5 \%} \mathrm{trichloroacetic} \mathrm{acid} \mathrm{(TCA)} \mathrm{and} \mathrm{further} \mathrm{partitioned} \mathrm{with}$ ethyl acetate, cyclopentane, and isopropanol (ratio of 100:99:1, v/v). The upper organic layer containing free SA was used for air-drying with nitrogen gas. The dry SA was-has again suspended in $1 \mathrm{~mL} 70 \%$ methanol and subjected to high-performance liquid chromatography (HPLC) using a Shimadzu device outfitted with a fluorescence indicator (Shimadzu RF-10AxL) with excitation at $305 \mathrm{~nm}$ and emission at $365 \mathrm{~nm}$ filled with a C18 reverse-phase HPLC column (HP Hypersil ODS, particle size $5 \mu \mathrm{m}$, pore size $120 \AA$, Waters). The flow rate was maintained at $1.0 \mathrm{~mL} / \mathrm{min}$.

\subsection{Statistical analysis}

All experiments were replicated three times, and each replicate was comprised of six plants. Data were statistically evaluated with Duncan multiple range tests and $t$-tests where appropriate, using SAS version 9.2 software (Cary, NC, USA).

\section{Results}

\subsection{In vitro antifungal assay}

The in vitro antifungal activity of PGPR B. aryabhattai SRB02 was assessed against pathogenic Fusarium oxysporum in dual culture. The results revealed that the PGPR B. aryabhattai SRB02 significantly inhibited the growth of pathogenic F. oxysporum, as shown in Figure S1.

\subsection{Response of tomato cultivars under pathogenic infection by $F$. oxysporum}

To determine the response of four tomato cultivars, the plants were challenged with a spore suspension of the pathogen. The pathogen was applied to the exposed roots of tomato plants and incubated under higher relative humidity to create a conducive environment for successful infection. After $14 \mathrm{~d}$ of inoculation, the cultivars revealed a differential level of tolerance to the pathogen (Figure 1). The plant tolerance level was determined based on the symptomatology (severity of plant wilting). In the susceptible plants, clear symptoms of wilting were evident. Susceptible plants were also observed with retarded growth as compared to the tolerant 
plants. Based on the plant growth attributes and resistance level, as shown in Figure 1, the most tolerant and susceptible tomato cultivars were selected for further experiments.

\subsection{Plant growth-promoting and ameliorative effects of B. aryabhattai SRBO2 against FOL}

Based on screening, the plant-growth-promoting and biocontrol efficiency of PGPR B. aryabhattai SRB02 against a virulent strain of $F$. oxysporum was investigated in both the selected tolerant and susceptible varieties (Figure 2). B. aryabhattai SRB02 significantly promoted plant growth, and interestingly reduced the disease in both tolerant and susceptible tomato cultivars (Figure 2).

The growth-related traits of the disease-tolerant plants were significantly improved when applied with SRB02 alone. The plant height (PH) was improved by $37.4 \%$, while RL was improved by $26.8 \%$ as compared to the water-treated control plants. Other traits including seedling FW, seedling DW, and chlorophyll content were also improved by $15.3 \%, 23.3 \%$, and $5.8 \%$, respectively. A similar trend was also observed when the tolerant plants were treated with the pathogen and SRB02 together, compared to the pathogen-treated plants. The PH, RL, seedling FW, DW, and chlorophyll content were improved by $124 \%, 6.4 \%, 15.8 \%, 42.3 \%$, and $39.7 \%$, respectively, compared to the plants inoculated with the pathogen alone. SRB02 also improved the growth attributes of the disease-susceptible plants with or without co-treatment by the pathogen. The PH of the disease-susceptible plants was improved by $14.1 \%$ with the application of SRB02 in comparison with the watertreated control plants; however, the increase in PH was significantly greater $(105.7 \%)$ in plants treated with SRB02 and F. oxysporum combined as compared to the pathogen-treated plants. Likewise, other traits were also improved in plants treated with PGPR alone as compared to the water-treated plants and also in the PGPR and pathogen co-treated susceptible plants in comparison with the plants treated with the pathogen alone. The RL, seedling FW, seedling DW, and chlorophyll content were improved by $9 \%$ and $44.5 \%, 10.4 \%$ and $32.6 \%$, $3 \%$, and $24.6 \%$, and $4 \%$ and $61.3 \%$ in plants treated with SRB02 alone and in plants co-treated with PGPR and the pathogen, respectively (Figure 2, Table 1).

\subsection{B. aryabhattai regulates defense against $F$. oxysporum by modulating defense-related hormones in} tomato

Measurement of basal and induced levels of the plant defense-related hormones SA and JA following inoculation with FOL in the absence or presence of SRB02 revealed strict regulation of plant defense responses in SRB02-treated plants due to the regulation of the synthesis of both of these hormones (Figures 3 and 4). Interestingly, these results were observed in both the resistant and susceptible cultivars, indicating the high utility of SRB02 for field use even in susceptible crops. More specifically, SRB02-treated infected plants (tolerant and susceptible) produced significantly lower JA (11.10\% and $10.30 \%$, respectively) compared to control plants (Figure 3). Even the SRB02-treated plants in the absence of FOL accumulated lower JA (6.92\% and $17.91 \%)$.

Furthermore, SRB02 treatment with $F$. oxysporum-inoculated plants of the tolerant cultivar accumulated 48.48\% more SA compared to plants not treated with the PGPR. More interestingly, the response of the $F$. oxysporum-inoculated plants of the susceptible cultivar was more robust in the presence of SRB02, as these plants produced $74.60 \%$ more SA as compared to plants not treated with PGPR (Figure 4). However, no significant differences in SA accumulation were observed in SRB02-treated plants of either tolerant and susceptible cultivars in the absence of $F$. oxysporum. 


\subsection{B. aryabhattai SRBO2 regulates amino acids in plants with or without biotic stress}

The current study showed that B. aryabhattai SRB02 regulates amino acids in both disease-tolerant and susceptible tomato plants in the presence or absence of $F$. oxysporum (Table 2). Under pathogenic infection by F. oxysporum, B. aryabhattai SRB02 inoculation significantly enhanced aspartic acid (115.57\% and 147.48\%), threonine (123.18\% and 118.56\%), serine (123.13\% and 158.91\%), glutamic acid (4.86\% and 157.89\%), glycine $(131.82 \%$ and $143.58 \%)$, alanine $(99.61 \%$ and $109.67 \%)$, valine $(98.13 \%$ and $74.62 \%)$, methionine (239.06\% and $172.93 \%)$, isoleucine (42.60\% and $97.82 \%)$, leucine (103.21\% and 58.03\%), tyrosine (138.45\% and $65.45 \%)$, phenylalanine $(39.86 \%$ and $34.16 \%)$, lysine $(113.15 \%$ and $98.03 \%)$, histidine $(98.42 \%$ and $111.74 \%)$, arginine (108.69\% and $157.18 \%)$, and proline (90.09\% and $115.25 \%)$ in disease-susceptible and tolerant tomato plants, respectively (Table 2). Only cysteine was decreased by $9.65 \%$ and $21.82 \%$ in $B$. aryabhattai SRB02 applied to susceptible and tolerant plants, respectively (Table 2).

Likewise, in the absence of the pathogen, B. aryabhattai SRB02 significantly enhanced aspartic acid (3.35\% and $24.98 \%)$, threonine (32.99\% and $118.56 \%)$, glutamic acid (4.86\% and $157.89 \%)$, glycine (30.78\% and $143.58 \%)$, alanine $(29.70 \%$ and $4.65 \%)$, cysteine $(44.22 \%$ and $60.20 \%)$, valine $(21.91 \%$ and $31.81 \%)$, methionine (132.35\% and 31.17\%), isoleucine ( $97.76 \%$ and $29.48 \%)$, leucine (36.52\% and 32.40\%), phenylalanine (114.92\% and $77.20 \%)$, histidine $(22.81 \%$ and $41.48 \%)$, and arginine (35.98\% and $23.95 \%)$ in the susceptible and tolerant plants, respectively (Table 2). However, B. aryabhattai SRB02 showed an increase in serine-intolerant $(9.73 \%)$ plants and a decrease of $13.22 \%$ in susceptible plants. Tyrosine was increased by $45.03 \%$ only in the tolerant plants when applied with PGPR, while it was decreased by $51.52 \%$ in susceptible plants. Similarly, lysine was increased $(35.12 \%)$ in the PGPR-applied tolerant plants, while no significant difference was observed in the susceptible plants. In contrast, proline was increased by $35.77 \%$ only in susceptible plants, while no significant difference was recorded in intolerant plants when challenged with PGPR (Table 2).

\section{Discussion}

The use of microbial-based techniques in the management of plant diseases has gained significant attention in recent years. In particular, PGPRs and their interactions with the plants under biotic or abiotic stress are gaining importance, with the ultimate aim of improvement in the protection of crops and increases in agricultural production. These biocontrol approaches are eco-friendly and are becoming very popular, reliable, and long-lasting. Plant growth improvement by PGPR is one of the outstanding characteristics of these naturally occurring microbes. The improvements in plant growth and its ameliorating abilities with regard teabout plant diseases are determined by the interactions between the host plant and PGPR (Vejan et al., 2016). PGPR improves plant growth and health by direct or indirect mechanisms that can overcome diseases. The plant growth-promoting activity of PGPR bacteria has been reviewed in detail by d Santoyo et al. (2016) (Xia et al., 2015; Santoyo et al., 2016). Bacillus and Pseudomonas species are widely known as invaluable resources for plant growth promotion and the suppression of disease symptoms (Sundaramoorthy \& Balabaskar, 2013; Chaves-López et al., 2015). Over the last few decades, several studies have reported on the beneficial aspects of Bacillus spp. as biocontrol and biofertilizer agents; e.g., Bacillus licheniformis, Bacillus subtilis, Bacillus cereus, Bacillus pumilus, and Bacillus amyloliquefaciens (Pane \& Zaccardelli, 2015; Han et al., 2016). The plant growth promotion and other beneficial aspects of Bacillus strains can be attributed to their ability to 
$\beta 13$ enhance the production of phytohormones such as auxin (IAA), ethylene, and gibberellic acid (Gamalero \& 314 Glick, 2011).

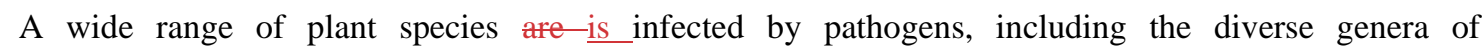
Alternaria, Botrytis, Fusarium, and Rhizoctonia. These pathogens result in severe losses to crop yield and productivity, thereby posing a threat to food security. F. oxysporum is a devastating fungal pathogen that attacks the vascular system and causes severe damages to tomato crops across the globe. Conversely, microbes, or PGPRs, found in the rhizosphere of plants are directly associated with roots and are a vital source for plant growth promotion and suppression of soilborne plant pathogens such as $F$. oxysporum. To isolate and evaluate the beneficial role of PGPR, an appropriate in vitro experimental setup is required. Shahzad et al. (2017) (Shahzad et al., 2017a) reported plant growth promotion by endophytic bacteria RWL-1 against the pathogenic infection by $F O L$ in tomato. In addition $\underline{A l s o}$, it was recently reported that B. aryabhattai SRBO2 plays a role in oxidative and nitrosative stress tolerance and promotes the growth of soybean and rice plants by modulating the production of phytohormones (Park et al., 2017a). However, it was not clear whether B. aryabhattai SRB02 could be used to rescue the plants from biotic stress. Hence, in the present study, we subjected disease-tolerant and susceptible tomato plants to the PGPR B. aryabhattai SRB02 in the presence and absence of a virulent strain of FOL, hypothesizing that SRB02 would rescue the plants from the disease and improve their growth under stress conditions. Prior toBefore inoculation by the pathogen, tomato plants were treated with a cell suspension of $B$. aryabhattai SRB02. The SRB02 application improved the disease tolerance level of the infected plants. In a previous study by Shahzad et al. (2017) (Shahzad et al., 2017a), PGPRs were shown to enhance plant growth, reduce infection by the pathogen, and result in improved disease tolerance.

The present study showed that under pathogenic infection, the PGPR association rescued the plants from disease and enhanced plant growth and biomass. This result might occur by restricting the pathogenic fungus, enhancing nutrient uptake, and producing phosphate solubilization substances, or by induction of phytohormonal biosynthesis. The present findings further strengthen the role of Bacillus species as a PGPR and biocontrol agent, as reported by numerous researchers, against diverse diseases in various plant species, such as root wilting, damping off, fusarium wilt, ring rot, and charcoal rot in tomato, soybean, banana, apple, and common bean, respectively (Yu et al., 2002; Vitullo et al., 2012; Wang \& Fobert, 2013; Chen et al., 2016; Torres et al., 2016). The current findings also indicate that PGPR strains producing bioactive components may suppress the negative effects of pathogenesis and biotic stress in infected plants. In addition, our study also confirmed and exhibited similar results to previous reports that organic acids, as one of the many components produced by Bacillus species, can help rescue the plant from the disease. Moreover, PGPR produces siderophores and organic acids, which mitigate the negative effects of pathogen-infected sunflower plants (Waqas et al., 2015). From these studies, it is evident that biotic stress-related ameliorative effects are commonly regulated by endogenous phytohormones such as SA and JA. Under normal and stress conditions, phytohormone signaling and crosstalk play a vital role in plant growth and development. Accordingly, in the present study, we found that inoculation with PGPR B. aryabhattai SRBO2 extensively modulated the endogenous levels of JA and SA. Our findings are in conformityconform with previously elucidated phytohormonal regulation; i.e., increased SA (Figure 4) and reduced JA (Figure 3) with PGPR, as revealed by independent studies (Khan et al., 2015; Waqas et al., 2015; Shahzad et al., 2016, 2017b; Ali et al., 2017) comparing plants in the presence or absence of biotic stress. 
354 Author Contributions: RBSN performed the experiments and analyzed the data. RBSN, RT, and RS drafted 355 the manuscript.MS, WA, and RBSN prepared illustrations, figures, tables, and references. B-WY, AH edited 356 the manuscript. B-WY contributed critical comments to the draft and approved the manuscript. All authors 357 contributed to the article and approved the submitted version.

358 Funding: This research was supported by Kyungpook National University Research Fund, 2019.

359 Conflicts of Interest: The authors declare no conflict of interest 


\section{References}

Ali MW, Kim ID, Bilal S, Shahzad R, Saeed MT, Adhikari B, Nabi RBS, Kyo JR, Shin DH. 2017. Effects of bacterial fermentation on the biochemical constituents and antioxidant potential of fermented and unfermented soybeans using probiotic bacillus subtilis (KCTC 13241). Molecules 22. DOI: 10.3390/molecules22122200.

Arnold AE, \& Lutzoni F. 2007. Diversity and host range of foliar fungal endophytes: are tropical leaves biodiversity hotspots? Ecology 88:541-549.

Backer R, Rokem JS, Ilangumaran G, Lamont J, Praslickova D, Ricci E, Subramanian S, Smith DL. 2018. Plant growth-promoting rhizobacteria: Context, mechanisms of action, and roadmap to commercialization of biostimulants for sustainable agriculture. Frontiers in Plant Science 871:1-17. DOI: 10.3389/fpls.2018.01473.

Bernier SP, Létoffé S, Delepierre M, Ghigo JM. 2011. Biogenic ammonia modifies antibiotic resistance at a distance in physically separated bacteria. Molecular Microbiology 81:705-716. DOI: 10.1111/j.13652958.2011.07724.x.

Bhardwaj D, Ansari MW, Sahoo RK, Tuteja N. 2014. Biofertilizers function as key player in sustainable agriculture by improving soil fertility, plant tolerance and crop productivity. Microbial Cell Factories 13:1-10. DOI: 10.1186/1475-2859-13-66.

Bilal S, Shahzad R, Khan AL, Kang SM, Imran QM, Al-Harrasi A, Yun BW, Lee IJ. 2018. Endophytic microbial consortia of phytohormones-producing fungus paecilomyces formosus $1 \mathrm{hl} 10$ and bacteria sphingomonas sp. lk11 to glycine max 1. regulates physio-hormonal changes to attenuate aluminum and zinc stresses. Frontiers in Plant Science 9:1-18. DOI: 10.3389/fpls.2018.01273.

Chaves-López C, Serio A, Gianotti A, Sacchetti G, Ndagijimana M, Ciccarone C, Stellarini A, Corsetti A, Paparella A. 2015. Diversity of food-borne Bacillus volatile compounds and influence on fungal growth. Journal of Applied Microbiology 119:487-499. DOI: 10.1111/jam.12847. 
alleviates bulk and nanoparticle Nd $2 \mathrm{O} 3$ toxicity in pumpkin: A physiological and molecular response. DOI: $10.1080 / 17435390.2016 .1202349$.

Compant S, Duffy B, Nowak J, Clément C, Barka EA. 2005. Use of plant growth-promoting bacteria for biocontrol of plant diseases: Principles, mechanisms of action, and future prospects. Applied and Environmental Microbiology 71:4951-4959. DOI: 10.1128/AEM.71.9.4951-4959.2005.

Costa LEDO, Queiroz MVD, Borges AC, Moraes CAD, \& Araújo EFD. 2012. Isolation and characterization of endophytic bacteria isolated from the leaves of the common bean (Phaseolus vulgaris). Microbiology

Enyedi AJ, Yalpani N, Silverman P, Raskin I. 1992. Localization, conjugation, and function of salicylic acid in tobacco during the hypersensitive reaction to tobacco mosaic virus. Proceedings of the National Academy of Sciences of the United States of America 89:2480-2484. DOI: 10.1073/pnas.89.6.2480.

Ernst M, Mendgen KW, Wirsel SGR, Phytopathologie L, Biologie F, Konstanz U, Konstanz D-. 2003. Endophytic Fungal Mutualists : Seed-Borne Stagonospora Spp . Enhance Reed Biomass Production in Axenic Microcosms. 16:580-587.

Gamalero E, Glick BR. 2011. Bacteria in Agrobiology: Plant Nutrient Management. DOI: 10.1007/978-3-64221061-7.

Gill SS, Hasanuzzaman M, Nahar K, Macovei A, Tuteja N. 2013. Importance of nitric oxide in cadmium stress tolerance in crop plants. Plant Physiology and Biochemistry 63:254-261. DOI:

Glick BR. 1995. The enhancement of plant growth by free-living bacteria. Canadian Journal of Microbiology 41:109-117. DOI: 10.1139/m95-015. rhizobacteria for sustainable development in agriculture. Microbiological Research 206:131-140. DOI: 10.1016/j.micres.2017.08.016. 
411 Han R, Wang H, Hu ZZ, Kumar A, Li W, Long LN, Schemm JKE, Peng P, Wang W, Si D, Jia X, Zhao M, 412 Vecchi GA, LaRow TE, Lim YK, Schubert SD, Camargo SJ, Henderson N, Jonas JA, Walsh KJE. 2016. An assessment of multimodel simulations for the variability of Western North Pacific tropical cyclones and its association with ENSO. Journal of Climate 29:6401-6423. DOI: 10.1175/JCLI-D-15-0720.1.

Hanson PM, Yang RY. 2016. Epidural Analgesia Inhibits the Renin and Aldosterone Response to Surgery. World Vegetable Center. Ekin J. 2:1-10. DOI: 10.1111/j.1399-6576.1979.tb01450.x.

Jing Y de, He Z li, Yang X e. 2007. Role of soil rhizobacteria in phytoremediation of heavy metal contaminated soils. Journal of Zhejiang University. Science. B. 8:192-207. DOI: 10.1631/jzus.2007.B0192.

Jones JB, Zitter TA, Momol MT, Miller SA. 2014. Compendium of tomato diseases second edition. :176.

Khan AL, Hussain J, Al-Harrasi A, Al-Rawahi A, Lee IJ. 2015. Endophytic fungi: Resource for gibberellins and crop abiotic stress resistance. Critical Reviews in Biotechnology 35:62-74. DOI: $10.3109 / 07388551.2013 .800018$.

Khan N, Mishra A, Nautiyal CS. 2012. Paenibacillus lentimorbus B-30488 r controls early blight disease in tomato by inducing host resistance associated gene expression and inhibiting Alternaria solani. Biological Control 62:65-74. DOI: 10.1016/j.biocontrol.2012.03.010.

Khan AL, Waqas M, Asaf S, Kamran M, Shahzad R, Bilal S, Khan MA, Kang SM, Kim YH, Yun BW, AlRawahi A, Al-Harrasi A, Lee IJ. 2017. Plant growth-promoting endophyte Sphingomonas sp. LK11 alleviates salinity stress in Solanum pimpinellifolium. Environmental and Experimental Botany 133:5869. DOI: 10.1016/j.envexpbot.2016.09.009.

Kloepper JW, Lifshitz R, Zablotovicz RM. 1989. Free-living bacteria inocula for enhancing crop productivity . Trends Biotechnol 7 : 39-44. 7799:39-44. DOI: 10.1016/0167-7799(89)90057-7.

Lee TJ, Chau HM, Thi T, Ha T, Yi GH, Park DJ, Kim H, Kim NS, Park CK, Cho WD. 2012. Yield and Fruit Characteristics of Korean Tomato (Lycopersicon esculentum Mill.) Cultivars Established at Different Cropping Seasons in Hanoi, Vietnam. Korean Journal of International Agriculture 24:309-315. 
Lee J-Y, Jun N-R, Yoon D, Shin C, Baik I. 2015. Association between dietary patterns in the remote past and telomere length. European Journal of Clinical Nutrition 69:1048-1052. DOI: 10.1038/ejcn.2015.58.

Lichtenzveig J, Anderson J, Thomas G, Oliver R. 2006. Inoculation and growth with soil borne pathogenic fungi. : $1-10$.

Lugtenberg B, Kamilova F. 2009. Plant-Growth-Promoting Rhizobacteria. DOI: 10.1146/annurev.micro.62.081307.162918.

Mahmood T, Gupta KJ, Kaiser WM. 2009. Cadmium Stress Stimulates Nitric Oxide Production By Wheat Roots. Pak. J. Bot 41:1285-1290.

Martínez-Hidalgo P, García JM, Pozo MJ. 2015. Induced systemic resistance against Botrytis cinerea by Micromonospora strains isolated from root nodules. Frontiers in Microbiology 6:1-11. DOI: 10.3389/fmicb.2015.00922.

Martínez-Viveros O, Jorquera MA, Crowley DE, Gajardo G, Mora ML. 2010. Mechanisms and practical considerations involved in plant growth promotion by Rhizobacteria. Journal of Soil Science and Plant Nutrition 10:293-319. DOI: 10.4067/S0718-95162010000100006.

McCloud ES, Baldwin IT. 1997. Herbivory and caterpillar regurgitants amplify the wound-induced increases in jasmonic acid but not nicotine in Nicotiana sylvestris. Planta 203:430-435. DOI: $10.1007 / \mathrm{s} 004250050210$.

Pailan S, Gupta D, Apte S, Krishnamurthi S, Saha P. 2015. Degradation of organophosphate insecticide by a novel Bacillus aryabhattai strain SanPS1, isolated from soil of agricultural field in Burdwan, West Bengal, India. International Biodeterioration and Biodegradation 103:191-195. DOI: 10.1016/j.ibiod.2015.05.006.

Pane C, Zaccardelli M. 2015. Evaluation of Bacillus strains isolated from solanaceous phylloplane for biocontrol of Alternaria early blight of tomato. Biological Control 84:11-18. DOI: 10.1016/j.biocontrol.2015.01.005. 
Park YG, Mun BG, Kang SM, Hussain A, Shahzad R, Seo CW, Kim AY, Lee SU, Oh KY, Lee DY, Lee IJ, Yun BW. 2017a. Bacillus aryabhattai SRB02 tolerates oxidative and nitrosative stress and promotes the growth of soybean by modulating the production of phytohormones. PLoS ONE 12:1-28. DOI: 10.1371/journal.pone.0173203.

Park YG, Mun BG, Kang SM, Hussain A, Shahzad R, Seo CW, Kim AY, Lee SU, Oh KY, Lee DY, Lee IJ, Yun BW. 2017b. Bacillus aryabhattai SRB02 tolerates oxidative and nitrosative stress and promotes the growth of soybean by modulating the production of phytohormones. PLoS ONE 12:1-28. DOI: 10.1371/journal.pone.0173203

Pieterse CMJ, Zamioudis C, Berendsen RL, Weller DM, Van Wees SCM, Bakker PAHM. 2014. Induced Systemic Resistance by Beneficial Microbes. Annual Review of Phytopathology 52:347-375. DOI: 10.1146/annurev-phyto-082712-102340.

Pupin B, Nahas E. 2014. Microbial populations and activities of mangrove, restinga and Atlantic forest soils from Cardoso Island, Brazil. Journal of Applied Microbiology 116:851-864. DOI: 10.1111/jam.12413.

Ramesh A, Sharma SK, Sharma MP, Yadav N, Joshi OP. 2014. Inoculation of zinc solubilizing Bacillus aryabhattai strains for improved growth, mobilization and biofortification of zinc in soybean and wheat cultivated in Vertisols of central India. Applied Soil Ecology 73:87-96. DOI: 10.1016/j.apsoil.2013.08.009.

Rosier A, Medeiros FHV, Bais HP. 2018. Defining plant growth promoting rhizobacteria molecular and biochemical networks in beneficial plant-microbe interactions. Plant and Soil 428:35-55. DOI: 10.1007/s11104-018-3679-5.

Santoyo G, Moreno-Hagelsieb, Orozco-Mosqueda G del C, Ma Glick BR. 2016. Plant growth-promoting bacterial endophytes. Microbiological Research 183:92-99. DOI: 10.1016/j.micres.2015.11.008.

Seskar M, Shulaev V, Raskin I. 1998. Endogenous methyl salicylate in pathogen-inoculated tobacco plants. Plant Physiology 116:387-392. DOI: 10.1104/pp.116.1.387. 

pathogenic infections: An example of Bacillus amyloliquefaciens RWL-1 and Fusarium oxysporum f. sp. lycopersici in tomato. PeerJ 2017:e3107. DOI: 10.7717/peerj.3107.

Shahzad R, Khan AL, Bilal S, Asaf S, Lee IJ. 2017b. Plant growth-promoting endophytic bacteria versus pathogenic infections: An example of Bacillus amyloliquefaciens RWL-1 and Fusarium oxysporum f. sp. lycopersici in tomato. PeerJ 2017:e3107. DOI: 10.7717/peerj.3107.

Shahzad R, Waqas M, Khan AL, Asaf S, Khan MA, Kang SM, Yun BW, Lee IJ. 2016. Seed-borne endophytic Bacillus amyloliquefaciens RWL-1 produces gibberellins and regulates endogenous phytohormones of Oryza sativa. Plant Physiology and Biochemistry 106:236-243. DOI: 10.1016/j.plaphy.2016.05.006.

Shittu HO, Castroverde DCM, Nazar RN, Robb J. 2009. Plant-endophyte interplay protects tomato against a virulent Verticillium. Planta 229:415-426. DOI: 10.1007/s00425-008-0840-z.

Shivaji S, Chaturvedi P, Begum Z, Pindi PK, Manorama R, Padmanaban DA, Shouche YS, Pawar S, Vaishampayan P, Dutt CBS, Datta GN, Manchanda RK, Rao UR, Bhargava PM, Narlikar J V. 2009. Janibacter hoylei sp. nov., Bacillus isronensis sp. nov. and Bacillus aryabhattai sp. nov., isolated from cryotubes used for collecting air from the upper atmosphere. International Journal of Systematic and Evolutionary Microbiology 59:2977-2986. DOI: 10.1099/ijs.0.002527-0.

Shoresh M, Harman GE, Mastouri F. 2010. Induced Systemic Resistance and Plant Responses to Fungal Biocontrol Agents. Annual Review of Phytopathology 48:21-43. DOI: 10.1146/annurev-phyto-073009114450.

Singh M, Kumar A, Singh R, Deo K. 2017. Endophytic bacteria : a new source of bioactive compounds. 3 Biotech 7:1-14. DOI: 10.1007/s13205-017-0942-z.

Singh M, Singh D, Gupta A, Pandey KD, Singh PK, Kumar A. 2019. Plant Growth Promoting Rhizobacteria. In: PGPR Amelioration in Sustainable Agriculture. Elsevier, 41-66. DOI: 10.1016/B978-0-12-815879$1.00003-3$

Singh N, Srivastava G, Talat M, Raghubanshi H, Srivastava ON, Kayastha AM. 2014. Cicer a-galactosidase immobilization onto functionalized graphene nanosheets using response surface method and its 
applications. Food Chemistry 142:430-438. DOI: 10.1016/j.foodchem.2013.07.079.

Stout MJ, Kurabchew H, Leite GLD. 2017. Host-Plant Resistance in Tomato. Elsevier Inc. DOI: 10.1016/B9780-12-802441-6.00009-7.

Sundaramoorthy S, Balabaskar and P. 2013. Evaluation of Combined Efficacy of Pseudomonas fluorescens and Bacillus subtilis in Managing Tomato Wilt Caused by Fusarium oxysporum f. sp. lycopersici (Fol). Plant Pathology Journal12:154-161. DOI: 10.3923/ppj.2013.154.161.

Vejan P, Abdullah R, Khadiran T, Ismail S, Nasrulhaq Boyce A. 2016. Role of plant growth promoting rhizobacteria in agricultural sustainability-A review. Molecules 21:1-17. DOI:

Viljoen JJF, Labuschagne N, Fourie H, Sikora RA. 2019. Biological control of the root-knot nematode Meloidogyne incognita on tomatoes and carrots by plant growth-promoting rhizobacteria. Tropical Plant

Vitullo D, Di Pietro A, Romano A, Lanzotti V, Lima G. 2012. Role of new bacterial surfactins in the antifungal interaction between Bacillus amyloliquefaciens and Fusarium oxysporum. Plant Pathology 61:689-699. Pathogen Pseudomonas syringae through Endoplasmic Reticulum-Based Processes. PLoS ONE 8:1-13. biotic stress in sunflower through regulation of defence hormones, antioxidants and functional amino acids. European Journal of Plant Pathology 141:803-824. DOI: 10.1007/s10658-014-0581-8. 
Worku M, Sahe S. 2018. Review on Disease Management Practice of Tomato Wilt Caused Fusarium oxysporum in Case of Ethiopia. Journal of Plant Pathology \& Microbiology 9:9-12. DOI: 10.4172/21577471.1000460.

Xia J, Niu S, Ciais P, Janssens IA, Chen J, Ammann C, Arain A, Blanken PD, Cescatti A, Bonal D, Buchmann N, Curtis PS, Chen S, Dong J, Flanagan LB, Frankenberg C, Georgiadis T, Gough CM, Hui D, Kiely G, Li J, Lund M, Magliulo V, Marcolla B, Merbold L, Montagnani L, Moors EJ, Olesen JE, Piao S, Raschi A, Roupsard O, Suyker AE, Urbaniak M, Vaccari FP, Varlagin A, Vesala T, Wilkinson M, Weng E, Wohlfahrt G, Yan L, Luo Y. 2015. Joint control of terrestrial gross primary productivity by plant phenology and physiology. Proceedings of the National Academy of Sciences of the United States of America 112:2788-2793. DOI: 10.1073/pnas.1413090112.

Yoo SJ, Weon HY, Song J, Sang MK. 2019. Induced tolerance to salinity stress by halotolerant bacteria bacillus aryabhattai H19-1 and B. Mesonae H20-5 in tomato plants. Journal of Microbiology and Biotechnology 29:1124-1136. DOI: 10.4014/jmb.1904.04026.

Yu GY, Sinclair JB, Hartman GL, Bertagnolli BL. 2002. Production of iturin A by Bacillus amyloliquefaciens suppressing Rhizoctonia solani. Soil Biology and Biochemistry 34:955-963. DOI: 10.1016/S00380717(02)00027-5.

Yun B, Skelly MJ, Yin M, Yu M, Mun B, Lee S, Hussain A, Spoel SH, Loake GJ. 2016. Nitric oxide and S nitrosoglutathione function additively during plant immunity. New Phytologist 211:516-526. DOI: 10.1111/nph.13903.

Zouari I, Jlaiel L, Tounsi S, Trigui M. 2016. Biocontrol activity of the endophytic Bacillus amyloliquefaciens strain CEIZ-11 against Pythium aphanidermatum and purification of its bioactive compounds. Biological Control 100:54-62. DOI: 10.1016/j.biocontrol.2016.05.012. 